\title{
Visually mediated trace conditioning in young rats: Evidence for cholinergic involvement in the development of associative memory
}

\author{
THOMAS B. MOYE \\ University of Colorado, Denver, Colorado \\ and \\ JERRY W. RUDY \\ University of Colorado, Boulder, Colorado
}

\begin{abstract}
Between 21 and 25 days of age, rats show considerable improvement in their ability to associate temporally separated events in a Pavlovian trace fear conditioning situation (Moye \& Rudy, in press). In the present study, it was shown that an appropriate dose of the cholinergic agonist physostigmine facilitated the otherwise poor, visually mediated trace conditioning performance of 21-day-old rats. In 25-day-old rats, the cholinergic antagonist scopolamine was shown to disrupt the otherwise strong trace conditioning performance exhibited by rats of this age. It is suggested that the development of associative memory processes that allow rats to integrate events separated in time may reflect the maturation of central cholinergic mechanisms.
\end{abstract}

Recently, we provided evidence suggesting that the visual memory processes that enable the young rat to associate temporally separate events undergo considerable maturation between 21 and 25 days of age (Moye \& Rudy, in press). Specifically, in a Pavlovian trace fearconditioning situation, 21-day-old rats appeared unable to associate a visual conditioned stimulus (CS) that was paired with a footshock unconditioned stimulus (US) when these events were separated in time by a 10-sec trace interval. Poor visually mediated trace conditioning was observed in the 21-day-olds despite the fact that rats this age can clearly associate the same CS and US events when they are presented in a temporally contiguous fashion (Moye \& Rudy, 1985, in press). By 25 days of age, however, young rats clearly demonstrated the ability to integrate visual CS and shock US events separated in time, since they exhibited strong conditioning with the same Pavlovian trace procedure that had failed to produce conditioning in the 21-day-olds.

The Pavlovian trace fear-conditioning procedure may be viewed as a simple memory task. Since the CS and US events are separated in time, successful conditioning with this procedure requires that a memory representation established by CS presentation persist over the trace

This research was supported by NSF Grant BNS8207654 from the National Science Foundation and PHS Grant DA03531-01 Al from the National Institute on Drug Abuse. We thank L. Camp for her comments on this manuscript. Reprint requests should be sent to Thomas B. Moye, Department of Psychology, Campus Box 345, University of Colorado, Boulder, CO 80309. interval so that it can be associated with the US when it occurs (Kamin, 1965; Pavlov, 1927). The sort of memory that is involved in the integration of temporally separated events has been referred to as associative memory by Revusky (1971; see also Watson, 1984). In the present study, we investigated the role of central cholinergic mechanisms in the emergence of visually mediated associative memory processes that enable the young rat to associate temporally separated events.

The importance of cholinergic systems in the emergence of mnemonic processes is suggested by a large body of pharmacological evidence. In general, pharmacological manipulations that interfere with central cholinergic transmission have been found to decrease performance on many memory tasks in a variety of different species. For example, administration of cholinergic antagonists, such as scopolamine or atropine, has been shown to disrupt short-term memory in mice (Alpern \& Marriott, 1973) and the working memory component of radial maze performance in rats (Wirsching, Beninger, Jhamandas, Boegman, \& El-Defrawy, 1984), to interfere with recognition memory and delayed matching-to-sample performance in monkeys (Aigner \& Mishkin, 1986; Penetar \& McDonough, 1983), and to impair the retention of recently learned information in humans (Bartus, Dean, Beer, \& Lippa, 1982; Drachman \& Leavitt, 1974).

There are also reports of enhancement of memory performance by the administration of drugs that facilitate cholinergic transmission. Appropriate dosages of an anticholinesterase, such as physostigmine, have been shown to improve recall in monkeys on a delayed recognition 
task (Aigner \& Mishkin, 1986) and a visual delayed response task (Bartus, 1979). In humans, anticholinesterases can improve memory performance in normal young and aged adults (Davis, Mohs, \& Tinklenberg, 1979; Davis et al., 1978; Drachman \& Sahakian, 1980), as well as patients suffering from memory impairments due to senile dementia of the Alzheimer's type (Summers, Majovski, Marsh, Tachiki, \& Kling, 1986).

Given that cholinergic mechanisms appear to be important in mnemonic processes, one possible explanation for the poor visually mediated associative memory performance that we have observed in 21-day-old rats could be that their cholinergic systems are immature and thus not yet fully functional. As cholinergic systems become more mature, however, associative memory processes should improve.

The general assumption guiding this investigation is that the visually mediated associative memory deficits displayed by 21-day-old rats may be due, at least in part, to a low level of function in central cholinergic systems. If this is the case, then it may be possible to improve the poor memory performance of young rats through pharmacological enhancement of cholinergic transmission. Additionally, if the emergence of memory processes is dependent on the development of cholinergic mechanisms, it should be possible to disrupt the superior memory performance of 25-day-olds by treatments that interfere with cholinergic transmission.

\section{EXPERIMENT 1a}

As noted above, 21-day-old rats condition poorly to a visual CS paired with a shock US when these events are separated in time by a 10-sec trace interval (Moye \& Rudy, in press). This suggests that visually mediated associative memory processes that enable the rat to maintain a representation of the CS over the trace interval may be immature in rats this age. In this experiment, we examined the effect of different doses of the cholinergic agonist physostigmine on the ability of 21-day-olds to learn a light-shock association when these events were separated in time. Physostigmine is an anticholinesterase, and thus enhances cholinergic transmission by inhibiting the degradation of acetylcholine in the synapse. If the poor trace conditioning performance of 21-day-olds is due to immature cholinergically mediated memory processes, then the enhancement of cholinergic transmission may improve the ability of the young pups to integrate temporally separated events.

\section{Method}

\section{Subjects}

The subjects were 24 Long-Evans-derived hooded rat pups that were 21 days old at the beginning of training. Pregnant breeders were checked for births each day between 7:00 and 9:00 a.m. A new litter was considered to be 0 days old. Each litter was culled to 9 pups 2-3 days after birth, and housed with the dam in a $45 \times 25 \times 20 \mathrm{~cm}$ Plexiglas maternity cage containing pine shavings. The dams had continuous access to Wayne laboratory chow and water. The pups were weaned when they were 23 days old. The sex of subjects was not recorded. The subjects were housed in a colony with a 12:12 light:dark cycle. The experiments took place between 2 and $11 \mathrm{~h}$ after lights on. In this experiment, the subjects were 21 days old at the beginning of training. Three litters each contributed 2 subjects to each of four experimental conditions ( $n=6$ per group).

\section{Apparatus}

Training and/or testing took place in a $27 \times 20 \times 10 \mathrm{~cm}$ clear Plexiglas chamber. The ceiling of the chamber was constructed of aluminum window screen. The grid floor was constructed from 2-mmdiam stainless steel bars spaced $6 \mathrm{~mm}$ apart. The grid floor was wired to deliver scrambled electric shock from a BRS constantcurrent shock source.

To monitor the activity levels of the subjects during testing, the chamber was equipped with an ultrasonic motion-detection device. The detector consisted of an ultrasonic transmitter and receiver, which transformed air current disturbances (caused by movement of a pup in the chamber) into relay closures that were recorded on a Commodore 64 computer. Relatively high levels of activity (e.g., walking, rearing, grooming, etc.) were translated into a high rate of relay closures. The transmitter and receiver were both $2.4 \mathrm{~cm}$ in diameter and mounted at one end of the chamber $2.5 \mathrm{~cm}$ above the grid floor, $5.0 \mathrm{~cm}$ from each other. The sensitivity of the detector was adjusted so that naive rat pups (from 15 to 30 days old) produced from 80 to 130 "activity counts" over a 1-min period (following a 5-min adaptation period).

The CS was a flashing light of 15-sec duration. The visual CS was produced by a clear $6-\mathrm{W}$ lamp mounted $40 \mathrm{~cm}$ above the grid floor directly over the Plexiglas experimental chamber. Measured at floor level, the intensity of this light was $54.1 \times 10^{1} \mathrm{~cd} / \mathrm{m}^{2}$. The visual stimulus flashed on and off at a rate of 4 times/sec. The 6-W lamp was the only source of illumination in the chamber.

The Plexiglas experimental chamber was enclosed in a light-tight, sound-attenuating shell. The dimensions of the interior of the shell were $55 \times 38 \times 45 \mathrm{~cm}$. White noise was present in the room that housed the chamber. The intensity of this noise, as measured inside the sound-attenuating shell, was approximately $60 \mathrm{~dB}$. Control equipment was located in a separate room.

\section{Procedure}

Training. Approximately $10 \mathrm{~min}$ prior to the training session, 21-day-old rats ( $n=6$ at each dose level) were given a subcutaneous (s.c.) injection of $0, .005, .01$, or $.1 \mathrm{mg} / \mathrm{kg}$ physostigmine salicylate (Sigma) mixed in a .9\% saline vehicle (1 cc/ $\mathrm{kg}$ volume). These dose levels were similar to those used by Aigner and Mishkin (1986) in a study that examined the effects of cholinergic drugs on primate memory performance.

Immediately prior to the training session, urination and defecation were stimulated in a subject by stroking the anogenital region with a small paint brush. Following this, the subject was placed in the experimental chamber.

After allowing the subject to adapt to the chamber for $5 \mathrm{~min}$, it was given a single session of 10 Pavlovian fear conditioning trials involving pairings of the light CS with the shock US. The US was a .5-sec, 1-mA scrambled shock applied through the grid floor. The intershock interval was $8 \mathrm{~min}$. The CS was $15 \mathrm{sec}$ in duration and terminated $10 \mathrm{sec}$ prior to US onset. Thus, there was a 10 -sec trace interval between the CS and US.

Testing. Pups were tested $24 \mathrm{~h}$ following training. In this experiment, no drugs were administered prior to the test. Each subject was again placed in the Plexiglas chamber and given a 1-min adaptation period. Following this, the subject's activity level in the absence of the tone CS was measured with the motion detector for $90 \mathrm{sec}$ (the pre-CS period). After the pre-CS period, the subject's activity level was measured for an additional $90 \mathrm{sec}$ while the light 
CS was on continuously (the CS-on period). This procedure provided a measure of each subject's activity level both in the absence and in the presence of the CS. Previously, we have shown that rat pups that associate the CS and US events become inactive, or "freeze," in the presence of the CS during such a test (Moye \& Rudy, 1985, in press). For purposes of analysis, a suppression ratio score was computed for each subject by dividing the number of activity counts recorded during the CS-on period by the total number of activity counts recorded during the pre-CS and CS-on periods. By this measure, strong conditioning is represented by a suppression ratio of zero, which indicates that ongoing activity was completely suppressed (as measured by the motion detector) by the CS. A ratio of .5 indicates that CS presentation had no effect on activity.

\section{Results}

Pre-CS levels of activity were comparable for all of the groups tested, with a range of 158 to 171 counts recorded during this $90-\mathrm{sec}$ period.

The suppression ratios obtained during the test are presented in Figure 1. Clearly, physostigmine administered prior to training had a dose-dependent effect on the amount of suppression observed $[F(3,20)=6.36$, $p<.05$ ]. Newman-Keuls post hoc comparisons $(\alpha=.05)$ revealed that the subjects that received the $.01-$ $\mathrm{mg} / \mathrm{kg}$ dose displayed significantly greater suppression than those that received only saline. No other groups differed reliably from the saline controls. Thus, the .01$\mathrm{mg} / \mathrm{kg}$ dose of physostigmine appears to have facilitated the trace conditioning performance in the 21-day-old pups.

\section{EXPERIMENT 1b}

The purpose of this experiment was to verify that the facilitative effect of the $.01-\mathrm{mg} / \mathrm{kg}$ dose of physostigmine

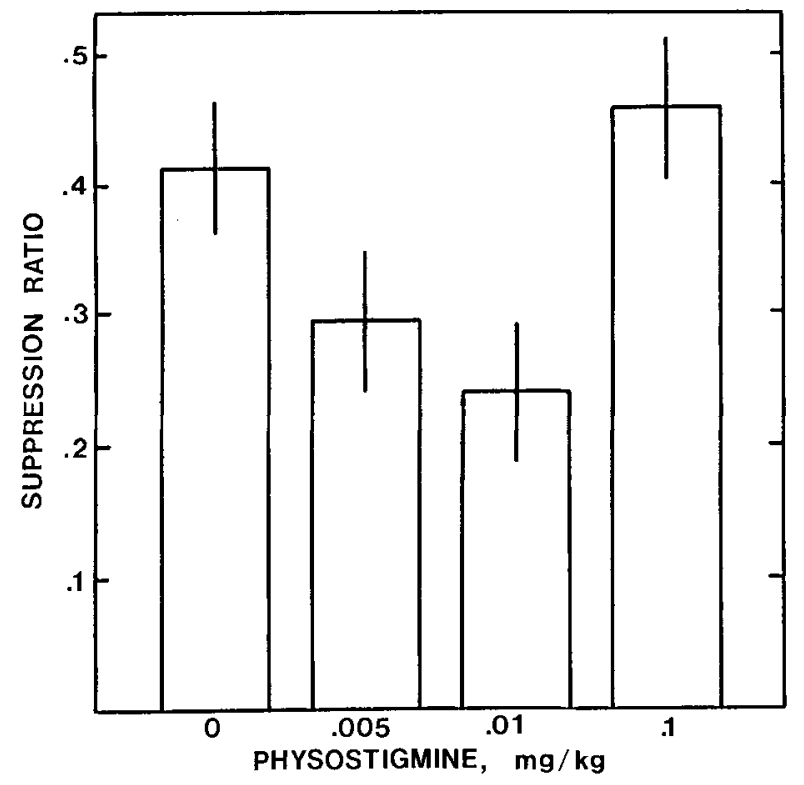

Figure 1. Mean suppression ratios obtained following different doses of physostigmine and a trace fear-conditioning session in Experiment 1a. Rats were 21 days old during conditioning. Lower suppression ratios indicate stronger conditioning. Vertical lines represent standard errors.

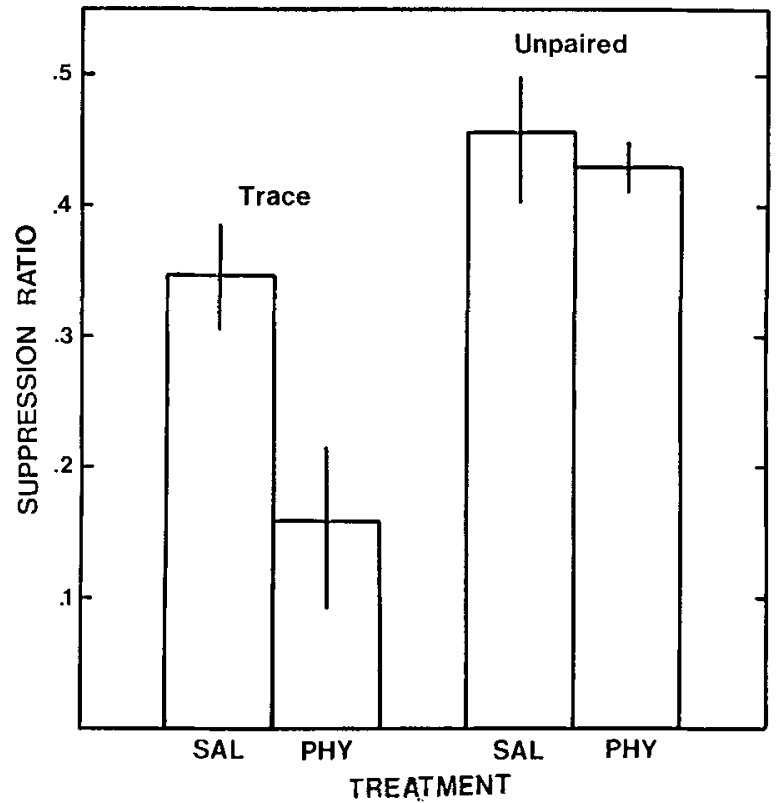

Figure 2. Mean suppression ratios obtained following administration of .01 $\mathrm{mg} / \mathrm{kg}$ physostigmine (PHY) or saline (SAL) and a session of either trace or unpaired light-shock presentations in Experiment $1 \mathrm{~b}$.

on trace conditioning performance reflects the effect of this dose on the associative memory processes that mediate conditioning. Conceivably, this dose of physostigmine could simply increase the tendency of pups to freeze after they have been exposed to lights and shocks, rather than improve their ability to associate temporally separate events. To address this nonassociative explanation, pups were administered either $.01 \mathrm{mg} / \mathrm{kg}$ physostigmine or saline, and given either paired (trace) presentations of the light and shock or explicitly unpaired CS-US events. If the effect of physostigmine is to improve the pups' ability to associate temporally separate CS and US events, then only the pups given paired presentations and physostigmine should show enhanced suppression.

\section{Method}

The subjects were 24 hooded rats (three litters each contributed 2 subjects to each of the four groups) that were 21 days old during training. Half of the subjects received $.01 \mathrm{mg} / \mathrm{kg}$ physostigmine prior to training; the other half received saline. Half of the drugtreated rats, and half of the control subjects received 10 light-shock pairings with a 10-sec trace interval (trace), as in Experiment 1a. The other subjects also received light-shock presentations, but the tone was presented at the temporal midpoint of the intershock interval (unpaired). Little or no conditioning, hence little suppression, would be expected to occur with such an arrangement.

\section{Results}

The suppression ratios are presented in Figure 2. There was a reliable effect of drug (physostigmine vs. saline) $[F(1,20)=6.2, p<.05]$ and of condition (trace vs. unpaired CS and US) $[F(1,20)=19.9, p<.05]$. The drug $x$ condition interaction did not reach statistical significance $[F(1,20)=2.9]$. Newman-Keuls post hoc com- 
parisons $(\alpha=.05)$ indicated that the subjects that received physostigmine and paired CS-US presentations exhibited significantly greater suppression than all other groups. No other comparisons reached significance. Thus, the facilitating effects of physostigmine administration appear to be on the associative memory processes that mediate trace conditioning, and not simply an increased tendency of pups to freeze in response to CS presentation during the test.

\section{EXPERIMENT 1c}

Since physostigmine has actions in both the peripheral and central nervous systems, it is possible that the facilitation of trace conditioning observed was due to its peripheral, rather than central, effects. In order to examine this issue, we conditioned rats under the influence of neostigmine, an anticholinersterase that does not penetrate the central nervous system (Feldman \& Quenzer, 1984). If the enhancement of trace conditioning by an anticholinesterase was due to a central effect, then neostigmine should not improve the suppression observed during a test.

\section{Method}

The subjects were 18 21-day-old hooded rats. Three litters each contributed 2 subjects to each of the three groups. Ten minutes prior to a conditioning session, different groups $(n=6)$ of rats were given an injection of 0 (saline), .005, or $.01 \mathrm{mg} / \mathrm{kg}$ neostigmine methylsulfate (Sigma). All subjects were then given a single session of 10 trace fear conditioning trials as described earlier. The trace interval was again $10 \mathrm{sec}$ for all groups. Testing took place $24 \mathrm{~h}$ later.

\section{Results}

The suppression ratios are presented in Figure 3. Clearly, neither dose of neostigmine produced an increase in the amount of suppression obtained during the test, relative to the saline group $[F(2,15)<1]$. This indicates that the facilitation produced by physostigmine in Experiments $\mathrm{la}$ and $\mathrm{lb}$ was not a peripheral effect, but was due to some action on the central nervous system.

\section{EXPERIMENT 1d}

The results of Experiments 1a-1c suggest that enhancement of cholinergic transmission by physostigmine improves the 21-day-old rat's ability to associate temporally separated events. However, it is also possible that physostigmine simply enhances what would otherwise be weakly expressed conditioning of any sort. To test this possibility, 21-day-old pups were given a conditioning session in which the CS and US were presented in a temporally contiguous fashion, but with parameters that result in a weak level of conditioning relative to that obtained with the trace procedure. If physostigmine simply improves conditioning in general, then administration prior to such a session should result in enhanced suppression during a test. On the other hand, if the effect of physostigmine

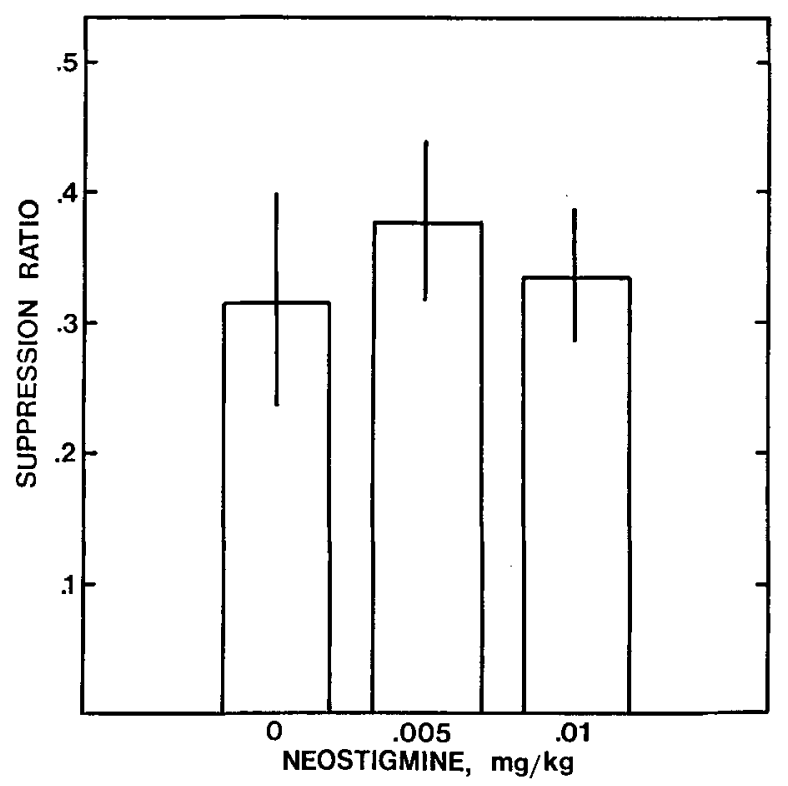

Figure 3. Mean suppression ratios obtained following different doses of neostigmine and a trace fear-conditioning session in Experiment 1c.

is to improve specifically the ability of pups to integrate temporally separate events, then it should have no effect on weak contiguous conditioning.

\section{Method}

The subjects were 2421 -day-old rats. Three litters each contributed 2 subjects to each of the four groups. The subjects in the contiguous groups were given fear-conditioning trials as before, except that (1) the offset of the CS was co-occurrent with US onset, and thus there was no trace interval, (2) only three CS-US pairings were given, and (3) the US intensity was only .4 mA. Subjects in the unpaired groups were given three explicitly unpaired presentations of the CS and weak US. Ten minutes prior to the conditioning session, half of the subjects in both the contiguous and unpaired groups were given an injection of $0.01 \mathrm{mg} / \mathrm{kg}$ physostigmine. The other half of the subjects were given saline injections. Testing took place $24 \mathrm{~h}$ after training, as described previously.

\section{Results}

The suppression ratios are presented in Figure 4. A twoway analysis of variance revealed that there was a significant main effect of condition (contiguous vs. unpaired) $[F(1,20)=13.4, p<.05]$, but no main effect of drug treatment (physostigmine vs. saline) and no condition $x$ drug interaction $[F \mathrm{~s}$ both $<1]$. This indicates that although weak conditioning occurred in the contiguous groups, physostigmine did not enhance the level of conditioning observed.

\section{Discussion}

The results of Experiments 1a-1d can be easily summarized. An appropriate dose of physostigmine appears to improve the trace conditioning performance of 21-dayold rats. Furthermore, this enhancement of performance 


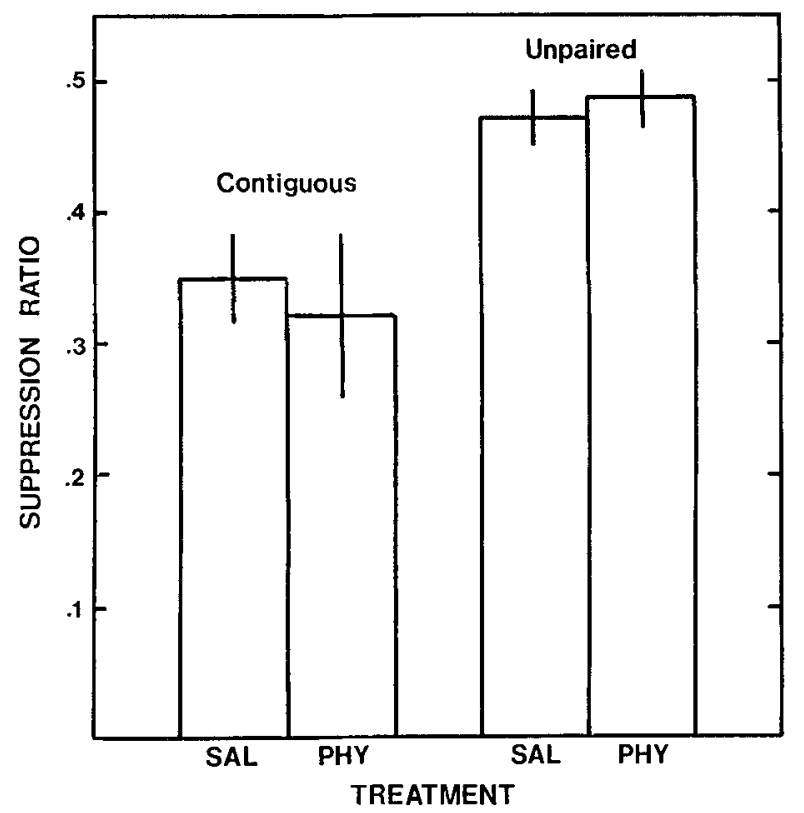

Figure 4. Mean suppression ratios obtained following administration of $.01 \mathrm{mg} / \mathrm{kg}$ physostigmine (PHY) or saline (SAL) and weak contiguous or unpaired light-shock presentations in Experiment 1d.

by physostigmine does not appear to be due to an increased tendency to freeze during a test or to a general enhancement of weak conditioning between contiguous events. Finally, the enhancement of trace conditioning appears to be due to a central action, since a peripherally acting anticholinesterase did not have a facilitative effect.

Between 21 and 25 days of age, the rat becomes increasingly proficient at integrating temporally separate events. The 21-day-old rat is quite poor at associating a light CS with a shock US when these events are separated by a 10-sec trace interval, whereas the 25-day-old demonstrates substantial conditioning with the same parameters (Moye \& Rudy, in press). The experiments described so far have shown that the deficit in the 21-day-olds can be alleviated to a large extent by a treatment that enhances central cholinergic transmission. This suggests that the emergence of the ability to integrate events separated in time may depend, at least in part, on the maturation of central cholinergic mechanisms.

\section{EXPERIMENT 2a}

The experiments so far have suggested that the development of central cholinergic mechanisms plays an important role in the emergence of the capacity to integrate temporally separate events. In the experiments that follow, we further examine the role of central cholinergic mechanisms in the emergence of trace conditioning capacity.

As noted earlier, by 25 days of age, rats are capable of conditioning to a visual CS when a 10-sec trace interval separates the CS and US events. If the development of central cholinergic mechanisms plays a role in the emergence of this associative memory capacity, it should be possible to disrupt the performance of 25 -day-olds on the trace procedure by interfering with cholinergic transmission. Thus, in this experiment, 25-day-old rats were administered scopolamine, a cholinergic antagonist that blocks muscarinic receptors, prior to a trace fearconditioning session. If cholinergic function is an important component of trace conditioning performance, then cholinergic blockade should interfere with the acquisition of a conditioned response during trace conditioning. It should not, however, interfere with learning an association between temporally contiguous events.

\section{Method}

The subjects were 36 hooded rats that were 25 days old during training. These subjects represented six different litters. Each litter contributed no more than 2 subjects to any one group. The apparatus was the same as in the previous experiments.

Three different groups of rats (trace) were given s.c. injections of 0 (saline), .2, or $1.0 \mathrm{mg} / \mathrm{kg}$ scopolamine hydrobromide (Sigma). Dose levels in this range have previously been shown to influence the spatial-memory performance of young rats (Rauch \& Raskin, 1984). Ten minutes after injection, the rats were placed individually in the conditioning chamber and given a session of 10 conditioning trials with a $10-\mathrm{sec}$ trace interval, as described earlier. Two other groups (contiguous) were conditioned with a standard procedure in which the 15-sec light CS terminated with the onset of the US. Thus, for these two groups, there was no trace interval. One contiguous group was given a saline injection prior to training; the other was administered $1.0 \mathrm{mg} / \mathrm{kg}$ scopolamine. These groups were included to see if scopolamine had any effect on conditioning between temporally contiguous events. A final group of subjects (unpaired) was given a saline injection, followed by a session of explicitly unpaired CS-US presentations. Testing took place $24 \mathrm{~h}$ after training, as in the previous experiments.

\section{Results}

The suppression ratios are presented in Figure 5. Clearly, scopolamine administered prior to training reduced the amount of suppression observed during the test in subjects conditioned with the 10-sec trace interval. An analysis of variance revealed a treatment effect $[F(5,30)$ $=26.8, p<.01$ ]. Newman-Keuls post hoc comparisons $(\alpha=.05)$ indicated that subjects that received saline and trace CS-US presentations produced suppression ratios significantly lower than did either of the trace scopolamine groups or the saline/unpaired group. Furthermore, there were no reliable differences between the saline/ unpaired group and the scopolamine groups. Finally, subjects given contiguous CS-US presentations did not differ from each other, indicating that scopolamine did not impair conditioning in general. Thus, the saline-injected rats were clearly able to associate the light and shock events when they were separated by a 10 -sec trace interval, whereas the subjects that received scopolamine prior to this training exhibited no evidence of having learned this relationship.

\section{EXPERIMENT 2b}

In the previous experiment, scopolamine was administered only prior to training and not before testing. For this reason, one possible explanation for the scopolamine 


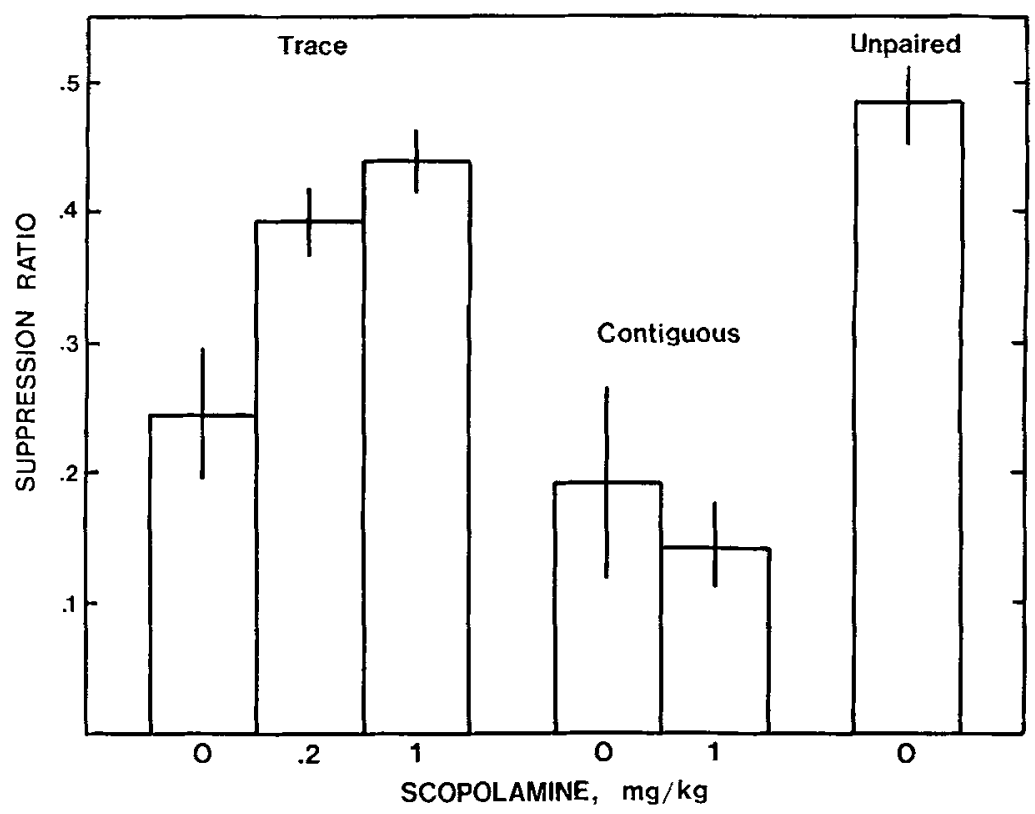

Figure 5. Mean suppression ratios obtained following different doses of scopolamine and a session of either trace of contiguous light-shock presentations in Experiment $2 \mathrm{a}$. The group given saline and unpaired CS-US presentations is included for comparison. Subjects were 25 days old during conditioning.

treated animals' failure to exhibit suppression during the test could be state-dependent forgetting. Since the rats were trained while in a particular drug state, and testing occurred in the absence of that drug, the internal contextual milieu may have been sufficiently different during the test to interfere with effective retrieval of the earlier conditioning episode (see Overton, 1966). To address this possibility, 25-day-old rats were conditioned and tested under the influence of scopolamine in order to provide a comparable internal context at both time points. If statedependent forgetting was responsible for the poor trace conditioning observed in Experiment 2a, then scopolamine given prior to training and testing should result in improved suppression during the test. However, if scopolamine were specifically degrading the ability of the subjects to condition in the trace situation, then scopolamine given during the test as well should have no effect.

\section{Method}

Eighteen 25-day-old rats were divided into three groups of 6 subjects each. Three litters each contributed 2 subjects to each group. Ten minutes prior to training, subjects in one group were given an injection of saline (SAL) and the other two groups were given $1.0 \mathrm{mg} / \mathrm{kg}$ scopolamine hydrobromide (SC-SAL and SC-SC). All subjects then received a session consisting of 10 visual fearconditioning trials with a $10-\mathrm{sec}$ trace interval as described above. Testing took place $24 \mathrm{~h}$ later. Ten minutes prior to the test, subjects in the saline group (SAL) and in one of the groups given scopolamine prior to training (SC-SAL) were given an injection of the saline vehicle. Subjects in the other scopolamine group (SC$\mathrm{SC}$ ) were given a second injection of $1.0 \mathrm{mg} / \mathrm{kg}$ scopolamine hydrobromide. Testing then took place as described previously.

\section{Results}

The suppression ratios are presented in Figure 6. An analysis of variance $[F(2,15)=10.8, p<.01]$ and subsequent Newman-Keuls post hoc comparisons $(\alpha=.05)$ indicated that subjects in the SAL group displayed significant suppression during the test relative to both Groups SC-SAL and SC-SC, which did not differ from each other. Thus, animals given scopolamine prior to training and testing did not display any more suppression than animals given scopolamine only prior to training. This suggests that state-dependent forgetting is not responsible for the apparent inability of scopolamine-treated pups to condition with the trace procedure.

\section{EXPERIMENT 2c}

The purpose of this experiment was to determine if the disruptive effect of scopolamine on trace conditioning performance was due to its effect on the central rather than the peripheral nervous system. Since methylscopolamine does not penetrate the central nervous system (Feldman \& Quenzer, 1984), we examined the effects of this anticholinergic on the trace conditioning performance of 25day-old rats. If scopolamine's disruptive effects are due to a central action, then methylscopolamine should have no effect on trace conditioning performance.

\section{Method}

The subjects were 1825 -day-old hooded rats. Three litters each contributed 2 subjects to each of three groups. Six rats (METH) 
were administered (s.c.) $1.0 \mathrm{mg} / \mathrm{kg}$ methylscopolamine (scopolamine methylbromide, Sigma), and another 6 subjects (SAL) were given a saline injection. Ten minutes later, they were given a session of 10 trace fear-conditioning trials as described above (trace). The other six animals (unpaired) were given a saline injection followed by a session of explicitly unpaired light-shock presentations.

\section{Results}

The suppression ratios are presented in Figure 7. Clearly, methylscopolamine administered prior to training had no effect on the amount of suppression obtained during the test. Regardless of whether training was preceded by an injection of saline or one of methylscopolamine, subjects in the trace conditioning groups were significantly suppressed relative to those in the unpaired group. Furthermore, the methylscopolamine and saline subjects in the trace groups did not differ from each other $[F(2,15)=8.2, p<.01$; Newman-Keuls post hoc comparisons, $\alpha=.05]$. Since a peripherally acting anticholinergic had no effect on trace conditioning performance, it appears that the disruptive effects of scopolamine observed in the previous experiments were due to actions on the central, rather than the peripheral, nervous system.

\section{GENERAL DISCUSSION}

Previously, we had shown that 21-day old rats condition poorly to a visual CS and shock US when these events are separated by a $10-\sec$ trace interval, but that, by 25 days of age, rats condition quite strongly with the same parameters (Moye \& Rudy, in press). In the present study, we found that pretraining administration of the anticholinesterase physostigmine significantly improved the trace

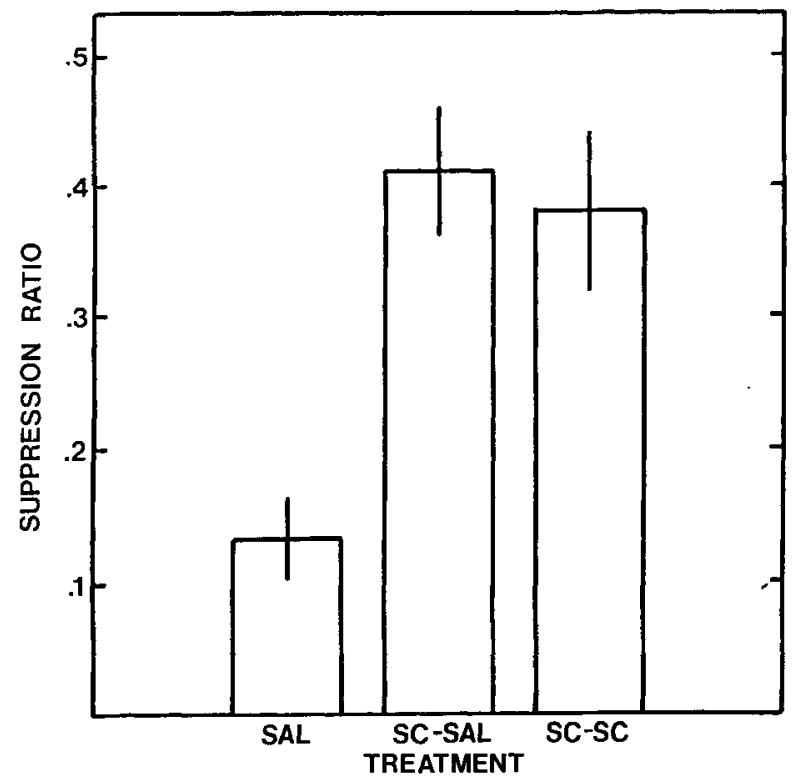

Figure 6. Mean suppression ratios obtained in Experiment 2b when scopolamine was administered prior to trace conditioning only (SC-SAL) or prior to conditioning and testing (SC-SC). Group SAL received saline prior to conditioning and testing.

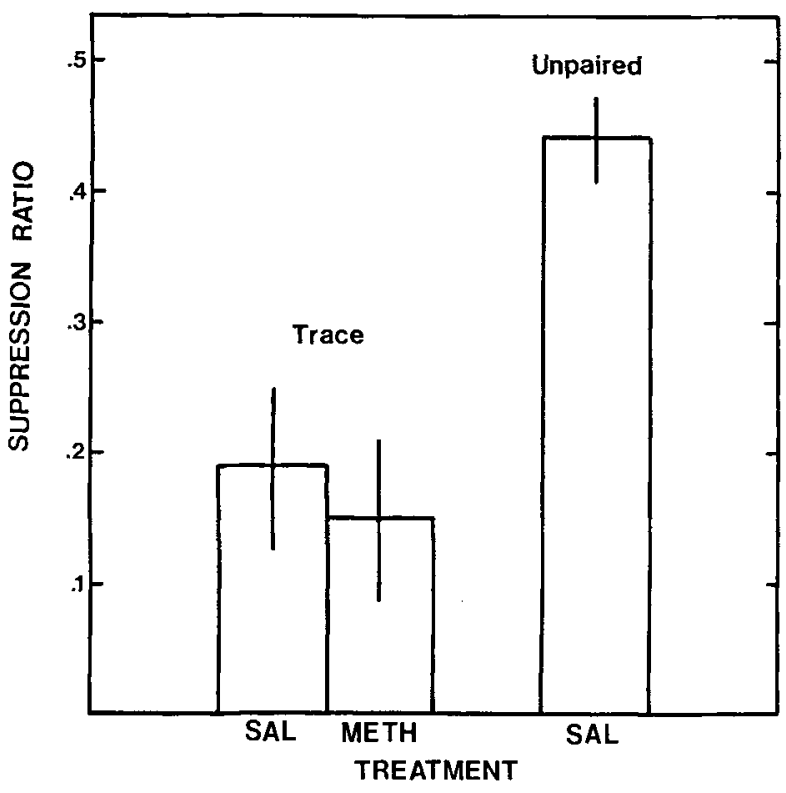

Figure 7. Suppression ratios obtained following methylscopolamine (METH) administration and trace conditioning in Experiment $2 \mathbf{c}$.

conditioning performance of 21-day-old subjects, presumably through the enhancement of central cholinergic transmission. In fact, the level of trace conditioning that occurred in the physostigmine-treated 21-day-olds was comparable to that observed in untreated 25-day-old rats. Thus, enhancement of central cholinergic transmission, in effect, resulted in precocial trace conditioning performance, with 21-day-old rats performing like 25-day-olds.

Further evidence for the importance of central cholinergic mechanisms in the emergence of visually mediated trace conditioning processes was provided in experiments in which scopolamine, a muscarinic cholinergic antagonist, interfered with trace conditioning performance in 25-day-old rats. In effect, cholinergic blockade at this age resulted in trace conditioning performance similar to that observed in much younger subjects. Taken together, the results of the physostigmine and scopolamine manipulations indicate that the maturation of central cholinergic mechanisms is an important factor in the emergence of the capacity to integrate temporally separate events.

Previously, we had suggested that the trace conditioning procedure might be viewed as a simple associative memory task (Moye \& Rudy, in press; see also Graves \& Solomon, 1985, Hebb, 1949, Kamin, 1965, and Pavlov, 1927, for a similar view of trace conditioning). In the trace procedure, the $\mathrm{CS}$ is not physically present at the time the US occurs. As a consequence of this arrangement, a representation, or memory trace, of the conditioned stimulus must persist during the interval between the CS and US in order for these events to become associated. Thus, the poor visual trace conditioning performance normally exhibited by 21 -day-old rats may be due to a rapid decay of the CS representation during the trace interval, such that it is not active in memory when the 
US occurs. If this characterization of the trace procedure is correct, then the enhancement of central cholinergic transmission in the 21-day-olds may have improved their capacity to retain a CS representation in memory over time. By the same token, interference with cholinergic transmission in 25-day-olds may have disrupted their ability to retain a CS representation during the trace interval, resulting in poor trace conditioning performance.

It is, of course, also possible that the cholinergic manipulations did not produce their effects by directly influencing associative memory processes per se, but rather by influencing the salience of the CS and US events. For example, if physostigmine simply increased the perceived intensity of either the shock or the visual stimulus during training, it could have resulted in stronger suppression during the test. Such an interpretation seems unlikely to be correct, however, since there was no evidence that the cholinergic manipulations had any effect on the level of conditioning obtained with temporally contiguous events.

\section{Central Cholinergic Development in the Rat}

The emergence of visually mediated trace conditioning capacity seems to occur relatively late during ontogenesis. Although the rat can condition to temporally contiguous light and shock presentations when only 17 days of age (Moye \& Rudy, 1985), evidence of learning when a 10-sec trace interval is interposed between these events does not emerge until 25 days of age (Moye \& Rudy, in press). Interestingly, many of the biochemical markers of central cholinergic development display a similarly protracted developmental time course, particularly when compared with the early-developing catecholaminergic systems (Johnston, 1985; Telang \& Enna, 1985). For example, levels of the synthetic enzyme for acetylcholine, choline acetyltransferase (CAT), are very low during the first postnatal week in the rat. However, over the next 3 weeks, central levels of this enzyme rise dramatically, reaching near adult levels by 28 days of age (Coyle \& Yamamura, 1976; Johnston, 1985). The development of midbrain and cortical cholinergic receptors also continues for a considerable period postnatally, with near-adult concentrations being reached around 29 days of age (Coyle \& Yamamura, 1976; Telang \& Enna, 1985). Thus, in rats, central cholinergic systems continue to develop until well past weaning at 21 days of age.

Although one cannot yet make causal statements regarding the relationship between the development of central cholinergic systems and visually mediated trace conditioning capability, the fact that the biochemical maturation of this transmitter system is correlated with the emergence of the capability to integrate temporally separate events is consistent with the notion that central cholinergic mechanisms play an important role in the performance of this task.

It should be noted that associative memory mediated by other sensory systems may not depend on central cholinergic development. For example, rats only 6 days old are able to integrate an olfactory CS with an illness US when these events are separated by a 15-min gap (Rudy \& Cheatle, 1979). It seems unlikely that maturation of central cholinergic systems could play an important role in the development of olfactory associative memory, since the ability to bridge temporal gaps emerges in this sensory system at a time when cholinergic mechanisms are still in an extremely immature state.

\section{The Hippocampus and Trace Conditioning}

Some recent conceptions of the role of the hippocampus in learning propose that one of its functions is to aid in the integration of events separated in time (Graves \& Solomon, 1985; Meck, Church, \& Olton, 1984; Port, Romano, Steinmetz, Mikhail, \& Patterson, 1986; Solomon, Vander Schaaf, Thompson, \& Weisz, 1986). Evidence for this view has come mainly from studies of the effects of hippocampal damage on rabbit nictitating membrane conditioning. Briefly, following hippocampectomy, the rabbits' capacity to learn a conditioned response when the CS and US are presented in a temporally contiguous fashion is unaffected. However, when a trace interval is interposed between the offset of the CS and onset of the US, rabbits with hippocampal damage exhibit a deficit in acquiring an adaptive conditioned response (Solomon et al., 1986).

This dissociation resulting from hippocampal damage is similar to the pattern of data obtained in the present study. Recall that although conditioning between contiguous events was not influenced by either physostigmine or scopolamine, trace conditioning processes were profoundly affected by these cholinergic agents. It is also interesting to note that one of the major inputs to the hippocampus, the septohippocampal pathway, is made up of predominantly cholinergic fibers (Cuello \& Sofroniew, 1984; Nicoll, 1985), and has been shown to be important in mnemonic processes (see Olton, 1982). These facts at least suggest the possibility that the emergence of the memory processes required for trace conditioning may depend, at least in part, on the maturation of the cholinergic input pathways to the hippocampus. Furthermore, it suggests that this system may undergo substantial maturation in the rat between 21 and 25 days of age.

It should be noted that cholinergic projections from the nucleus basalis to the forebrain have also been implicated in memory processes. For example, in rats, lesions of the nucleus basalis have been shown to disrupt some types of spatial memory performance (Murray \& Fibiger, 1985) and to impair retention of a passive avoidance response (Flicker, Dean, Watkins, Fisher, \& Bartus, 1983). In humans, degeneration of this cholinergic projection is thought to be involved in the memory impairments observed in Alzheimer's disease (e.g., Bartus et al., 1982).

Thus, at least two central cholinergic systems have been shown to play an important role in the mnemonic processes of adult organisms. However, the relative contributions of forebrain and hippocampal cholinergic systems to the emergence of associative memory processes remains to be determined. 


\section{REFERENCES}

Aigner, T. G., \& Mishkin, M. (1986). The effects of physostigmine and scopolamine on recognition memory in monkeys. Behavioral \& Neural Biology, 45, 81-87.

AlPERN, H. P., \& MARRIotT, J. G. (1973). Short-term memory: Facilitation and disruption with cholinergic agents. Physiology \& Behavior, 11, 571-575.

Bartus, R. T. (1979). Physostigmine and recent memory: Effects in young and aged nonhuman primates. Science, 206, 1087-1089.

Bartus, R. T., Dean, R. L., Beer, B., \& LiPPA, A. S. (1982). The cholinergic hypothesis of geriatric memory dysfunction. Science, 217, 408-416.

Coyle, J. T., \& Yamamura, H. I. (1976). Neurochemical aspects of the ontogenesis of cholinergic neurons in the rat brain. Brain Research, 118, 429-440.

Cuello, A. C., \& Sofroniew, M. V. (1984). The anatomy of the CNS cholinergic neurons. Trends in Neurosciences, 7, 74-78.

Davis, K., Mohs, R., \& TinklenberG, J. (1979). Enhancement of memory by physostigmine. New England Journal of Medicine, 301, 946.

Davis, K., Mohs, R., Tinklenberg, J., Pfefferbaum, A., HolUSTER, L., \& KOPELL, B. (1978). Physostigmine: Improvement of long-term memory processes in normal humans. Science, 201, 272-274.

Drachman, D. A., \& LeavitT, J. (1974). Human memory and the cholinergic system. Archives of Neurology, 30, 113-121.

Drachman, D. A., \& Sahakian, B. J. (1980). Memory and cognitive function in the elderly. Archives of Neurology, 37, 674-675.

Feldman, R. S., \& Quenzer, L. F. (1984). Fundamentals of neuropsychopharmacology. Sunderland, MA: Sinauer.

Flicker, C., Dean, R. L., Watkins, D. L., Fisher, S. K., \& Bartus, R. T. (1983). Behavioral and neurochemical effects following neurotoxic lesions of a major cholinergic input to the cerebral cortex in the rat. Pharmacology, Biochemistry \& Behavior, 18, 973-981.

Graves, C. A., \& Solomon, P. R. (1985). Age-related disruption of trace but not delay classical conditioning of the rabbits' nictitating membrane response. Behavioral Neuroscience, 99, 88-96.

HeBs, D. O. (1949). Organization of behavior: A neuropsychological theory. New York: Wiley.

Johnston, M. V. (1985). Neurotransmitters. In R. C. Wiggins, D. W. McCandless, \& S. J. Enna (Eds.), Developmental neurochemistry (pp. 193-224). Austin: University of Texas Press.

KAMIN, L. J. (1965). Temporal and intensity characteristics of the conditioned stimulus. In W. F. Prokasy (Ed.), Classical conditioning (pp. 118-147). New York: Appleton-Century-Crofts.

Meck, W. H., ChURCh, R. M., \& Olton, D. S. (1984). Hippocampus, time, and memory. Behavioral Neuroscience, 98, 3-22.

MoYe, T. B., \& RUDY, J. W. (1985). Ontogenesis of learning: VI. Learned and unlearned responses to visual stimulation in the infant hooded rat. Developmental Psychobiology, 18, 395-409.

MOYE, T. B., \& RUDY, J. W. (in press). Ontogenesis of trace conditioning in young rats: Dissociation of associative and memory processes. Developmental Psychobiology.
MurRay, C. L., \& Fibiger, H. C. (1985). Leaming and memory deficits after lesions of the nucleus basalis magnocellularis: Reversal by physostigmine. Neuroscience, 14, 1025-1032.

Nicoll, R. A. (1985). The septo-hippocampal projection: A model cholinergic pathway. Trends in Neurosciences, 8, 533-536.

OLTON, D. S. (1982). Hippocampal function and memory processes. In C. D. Woody (Ed.), Conditioning: Representation of involved neural functions (pp. 99-113). New York: Plenum Press.

OverTon, D. (1966). State-dependent learning produced by depressant and atropine-like drugs. Psychopharmacologia, 10, 6-31.

Pavlov, I. P. (1927). Conditioned reflexes (G. V. Anrep, Trans.), London: Oxford University Press.

Penetar, D., \& McDonough, J. (1983). Effects of cholinergic drugs on delayed match-to-sample performance of rhesus monkeys. Pharmacology, Biochemistry \& Behavior, 19, 963-967.

Port, R. L., Romano, A. G., Steinmetz, J. E., Mikhall, A. A., \& Patterson, M. M. (1986). Retention and acquisition of classical trace conditioned responses by rabbits with hippocampal lesions. $B e-$ havioral Neuroscience, 100, 745-752.

RAUCH, S. L., \& RASKIN, L. A. (1984). Cholinergic mediation of spatial memory in the preweanling rat: Application of the radial arm maze paradigm. Behavioral Neuroscience, 98, 35-43.

RevUSKY, S. (1971). The role of interference in association over a delay. In W. K. Honig \& P. R. James (Eds.), Animal memory (pp. 155213). New York: Academic Press.

Rudy, J. W. \& Cheatle, M. D. (1979). Ontogeny of associative learning: Acquisition of odor aversions by neonatal rats. In N. E. Spear \& B. A. Campbell (Eds.), Ontogeny of learning and memory (pp. 157188). Hillsdale, NJ: Erlbaum.

Solomon, P. R. , Vander SchaAf, E. R., Thompon, R. F., \& Weisz, D. J. (1986). Hippocampus and trace conditioning of the rabbit's classically conditioned nictitating membrane response. Behavioral Neuroscience, 100, 729-744.

Summers, W. K., Majovski, L. V., Marsh, G. M., Tachiki, K., \& KLING, A. (1986). Oral tetrahydroaminoacridine in long-term treatment of senile dementia, Alzheimer type. New England Journal of Medicine, 315, 1241-1245.

Telang, S. D., \& ENNA, S. J. (1985). Ontogenetic development of central nervous system neurotransmitter receptors. In R. C. Wiggins, D. W. McCandless, \& S. J. Enna (Eds.), Developmental neurochemistry (pp. 225-247). Austin: University of Texas Press.

W Atson, J. S. (1984). Memory in learning: Analysis of three momentary reactions of infants. In R. Kail \& N. E. Spear (Eds.), Comparative perspectives on the development of memory (pp. 159-179). Hillsdale, NJ: Erlbaum.

Wirsching, B. A., Beninger, R. J., Jhamandas, K., Boegman, R. J., \& El-Defrawy, S. R. (1984). Differential effects of scopolamine on working and reference memory in the radial arm maze. Pharmacology, Biochemistry \& Behavior, 20, 205-207.

(Manuscript received December 15, 1986; revision accepted for publication April 13, 1987.) 